\title{
ANALISIS PENGENDALIAN MUTU PADA INDUSTRI KERUDUNG
}

\author{
Upah, Sopyan Saori, Mochamad Maulana Hasan Jaelani, Wahyuni dan Ghivari \\ Lughi Ghartiwa \\ Universitas Muhammadiyah Sukabumi Jawa Barat, Indonesia \\ Email: sopyansauri@ummi.ac.id, Mariaulpah17@ummi.ac.id,maulana13@ummi.ac.id, \\ gghartiwa002@ummi.ac.id dan wahyuni063@ummi.ac.id.
}

\section{Abstract}

The purpose of this research is to analyze the defects of veil products by pareto diagram method and cause and effect, data analysis used is primary data analyzed based on check sheet and made pareto diagram and causal diagram. This research method uses primary data that is then analyzed based on check sheets and pareto diagrams and made causal diagrams, the results of this study showed that the production that failed in UMKM ANHA Store is an inappropriate color as much as $40 \%$ of the total number of failed products. After that followed by a wrinkled cloth by $60 \%$. By using a causal diagram it can be concluded that the main factors that cause damage or incompatibility in the manufacture of the veil are people and methods.

Keywords: quality control; pareto diagram; casual diagram

\begin{abstract}
Abstrak
Tujuan dari penelitian ini adalah untuk menganalisis cacat produk kerudung dengan metode Diagram Pareto dan Sebab Akibat, Analisis data yang peneliti gunakan adalah data primer yang dianalisis berdasarkan lembar cek dan dibuat diagram pareto dan diagram sebab akibat. Metode penelitian ini menggunakan data primer yang kemudian dianalisis berdasarkan lembar cek dan diagram pareto serta dibuat diagram sebab akibat, Hasil penelitian ini menunjukan bahwa produksi yang gagal di UMKM ANHA Store adalah warna yang tidak sesuai sebanyak $40 \%$ dari jumlah produk gagal secara menyeluruh. Setelah itu dilanjut dengan kain berkerut sebesar $60 \%$. Dengan menggunakan diagram sebab akibat dapat disimpulkan bahwa faktor utama yang menyebabkan kerusakan atau ketidaksesuaian pada pembuatan kerudung adalah orang dan metode.
\end{abstract}

Kata kunci: Pengendalian mutu; Diagram Pareto; Diagram Sebab Akibat.

\section{Pendahuluan}

Seiring dengan perkembangan dunia teknologi dan informasi pada saat ini khususnya dunia komputer berkembang sangat pesat, ditambah dengan adanya kehadiran teknologi informasi yang semakin berperan di dalam dunia pekerjaan (Nurkarsa, 2019).

Perkembangan teknologi informasi Banyak sekali pengaruh budaya yang berkembang pesat melalui media cetak atau elektronik. Arus informasi yang cepat 
Berdampak pada kehidupan masyarakat Indonesia termasuk dalam industri fashion. Fashion merupakan gerak masyarakat dimana orang mengekspresikan dan memakai gaya tertentu sesuai dengan zamannya (Sukendro, Destiarmand, \& Kahdar, 2016). Salah satu fashion tersebut adalah kerudung dan hijab. Apa yang terjadi di dalam bidang fashion saat ini adalah munculnya berbagai gaya kerudung dan hijab dikatakan sebagai pakaian muslim dengan berbagai merk. Desain kerudung dan hijab lebih modis bentuk, warna, polanya semuanya berbeda-beda, sehingga sangat populer dan menjadi trend terutama wanita muslimah kota-kota besar di indonesia. Hijab berkembang menjadi komoditas yang dapat memenuhi permintaan konsumen, yang merupakan isu penting yang menjadi perhatian sebagian besar wanita. Namun, ada beberapa bentuk dan gaya dikatakan mengabaikan nilai dan fungsi hijab dalam hukum islam sebagai penutup saat wanita muslim berada di tempat umum, auranya adalah untuk menghindari pandangan pria, bukan mudra besarnya. Hijab sekarang menjadi simbol apakah hanya berharga atau fungsional, tetapi dengan konotasi fetisisme. Kerudung dan jilbab sebagai sorban sudah tidak ada lagi fungsi dan makna islam diuraikan. Hijab digunakan untuk pesona atau pesona kebanyakan wanita muslim. Masalah ini tidak bisa tanpa peran desainer dan pengusaha sebagai produsen hijab untuk menciptakan produk yang baik dan berkualitas. Produk baik merupakan produk yang memiliki kualitas yang bagus dan sesuai dengan keinginan atau kemauan pelanggan dengan kecacatan yang rendah dan seminiminal mungkin. Pengendalian mutu merupakan kegiatan pemantauan, evaluasi serta upaya tindak lanjut dalam capaian suatu persyaratan mutu yang ditetapkan dalam produksinya (Zakariya, Mu'tamar, \& Hidayat, 2020). pengendalian mutu suatu perusahaan dilakukan oleh pengawas yang terpisah dari proses produksi. Jika suatu perusahaan mampu meminimalkan kecacatan produk, maka perusahaan memungkinkan mendapatkan keuntungan akan jauh lebih besar (Suwandi Ng, 2016). Kualitas merupakan indikator yang paling mendasar untuk menentukan kualitas produk yang dihasilkan perusahaan, karena tentunya perusahaan harus mementingkan kualitas agar perusahaan dapat memenuhi kebutuhan konsumen. Untuk menghasilkan produk yang berkualitas baik dari bahan baku, proses produksi hingga produk akhir, kualitas produksi menjadi salah satu perhatian utama suatu perusahaan.

ANHA Store adalah UMKM yang begerak di bidang Fashion kerudung. ANHA Store memiliki banyak jenis produk khusus salah satunya kerudung instan yang saat ini masih ada produk yang gagal atau produk cacat. Oleh karena itu perlu adanya suatu tindakan melalui pengendalian mutu atau kualitas produk dengan metode diagram pareto dan diagram sebab akibat (Fishbone) untuk mengetahui jumlah produk yang cacat dalam setiap produksi.

Ishikawa menytakan bahwa mutu merupakan kepuasan pelanggan atau konsumen. Oleh karena itu, setiap bagian dari proses dalam organisasi memiliki pelangga. Pengendalian mutu adalah mengembangkan, merancang, memproduksi, dan menyediakan produk dan layanan berkualitas yang paling ekonomis, berguna, dan selalu memuaskan bagi konsumen (Husni \& Putra, 2018). 
Diagram Pareto berasal dari nama Vilfredo Pareto yaitu seorang ekonom dari Italia pada abad ke-19 (1993). Diagram Pareto digunakan untuk membandingkan berbagai kategori acara yang disusun berdasarkan ukuran, dari yang terbesar di kiri hingga yang terkecil di kanan. Pengaturan ini akan membantu kami menentukan kepentingan atau prioritas kategori acara atau penyebab acara yang diteliti, atau mengidentifikasi masalah utama dalam proses tersebut (Jani \& Sugiono, 2014).

Diagram pareto adalah diagram batang dan diagram garis yang menggambarkan perbandingan setiap tipe data dengan keseluruhan. Dengan menggunakan diagram pareto, kita dapat melihat masalah mana yang mendominasi, sehingga dapat dicari prioritas pemecahannya. Fungsi diagram pareto adalah untuk mengidentifikasi atau menyeleksi masalah utama peningkatan kualitas dari yang terbesar sampai yang terkecil (Fakhri \& Kamal, 2010).

Diagram tulang ikan adalah alat visualisasi yang digunakan untuk mengidentifikasi, mengeksplorasi dan menggambarkan secara rinci secara grafis semua alasan yang terkait dengan masalah tersebut (Asmoko, 2013).

Diagram tulang ikan adalah suatu tindakan, jika akar permasalahan ditemukan, maka lebih mudah untuk melakukan langkah-langkah perbaikan. Manfaat diagram tulang ikan antara lain diagram kausalitas yang mudah dibaca, sehingga lebih memungkinkan orang menggunakan metode ini untuk mengetahui penyebab masalah yang berdampak, meningkatkan produktivitas, dan meningkatkan komunikasi internal dan eksternal (Hisprastin \& Musfiroh, 2021).

Dari urain diatas maka tujuan peneliti adalah menghitung jumlah kerudung yang di produksi oleh ANHA Store masih ada produk yang cacat apakah melebihi batas wajar atau tidak oleh karena itu perlu di adakannya pengendalian terhadap produk agar mengurangi jumlah produk yang cacat dengan menggunakan metode diagram pareto dan diagram sebab akibat.

Definisi kualitas produk memiliki arti yang sangat luas, Kualitas produk merupakan penentu kepuasan konsumen setelah membeli dan menggunakan produk. Kualitas produk merupakan salah satu bentuk nilai kepuasan yang kompleks (Amanah, 2010). Melalui kualitas produk yang baik maka permintaan konsumen terhadap produk dapat terpenuhi. Jika kualitas produk yang diterima lebih tinggi dari yang diharapkan maka kualitas produk yang dirasakan akan memuaskan (Amilia, 2017).

Menurut (Myers, Montgomery, \& Anderson-Cook, 2016) Kualitas kontrol adalah proses yang digunakan untuk memastikan tingkat kualitas suatu produk atau layanan. Pengendalian mutu adalah suatu kegiatan rekayasa dan manajemen di mana kita dapat mengukur karakteristik mutu produk, membandingkannya dengan spesifikasi atau persyaratan, dan mengambil ukuran kesehatan yang sesuai bila terdapat perbedaan antara tampilan sebenarnya dan tampilan standar.

Tujuan utama pengendalian kualitas adalah untuk memastikan bahwa kualitas produk atau layanan yang dihasilkan memenuhi standar kualitas yang ditetapkan dan ekonomis atau dengan biaya terendah (Ratnadi \& Suprianto, 2020). 
Penggunaan diagram Pareto adalah untuk menemukan atau mencari prioritas utama dari suatu masalah saat ini, dan itu merupakan kunci untuk menyelesaikan masalah saat ini dan membandingkannya dengan keseluruhan (Jani \& Sugiono, 2014).

Konsep dasar dari diagram tulang ikan atau diagram sebab akibat adalah masalah dasar terletak pada diagram sisi kanan atau kepala kerangka tulang ikan. 3 Penyebab masalahnya dijelaskan pada sirip dan duri. Menurut (Ochiai et al., 2004) Kategori penyebab yang awalnya digunakan sebagai titik awal masalah meliputi bahan baku, mesin dan peralatan, tenaga kerja, metode, alam / lingkungan dan pengukuran.

Penelitian ini diharapkan bermanfaat bagi banyak kelompok yang berkepentingan termasuk peneliti. Penelitian ini dapat menambah wawasan, pengalaman dan pengetahuan tentang pengendalian kualitas produk yang dihasilkan oleh perusahaan, sebagai sarana informasi dan hasil evaluasi yang konstruktif bagi perusahaan, serta memberikan informasi yang dapat membantu perusahaan dalam menghadapi dan mengantisipasi permasalahan terkait penelitian Investasikan. Selain itu juga dapat digunakan sebagai referensi atau bacaan untuk aspek-aspek lain yang terkait dengan penelitian, serta memberikan informasi dan pengetahuan serta wawasan tentang pelaksanaan pengendalian mutu.

\section{Metode Penelitian}

1. Jenis penelitian

Penelitian ini dilakukan pada UMKM yang bergerak dibidang fashion yaitu kerudung ANHA Store Kota Sukabumi. Lokasi penelitian ini dipilih secara terencana dengan menggunakan data perusahaan pada bulan November 2020.

Jenis penelitian yang digunakan oleh peneliti bersifat deskriptif kuantitatif. Penelitian kuantitatif meliputi pemilihan subjek, Teknik pengumpulan data (kuisioner, observasi, atau tet).

2. Populasi dan Sampel

Populasi pada penelitian ini adalah UMKM ANHA Store Kota Sukabumi dengan sampel penelitian adalah pemilik usaha atau manajer UMKM Mochi ANHA Store Kota Sukabumi.

3. Sumber Data

Sumber data yang digunakan dalam penelitian ini adalah data primer. Dimana data tersebut dikumpulkan dan diolah sendiri oleh peneliti secara langsung ke UMKM ANHA Store.

4. Metode Analisis Data

Setelah mendapatkan data dari satu bulan pengamatan yang dilakukan pada November 2020, langkah selanjutnya adalah menentukan prioritas penyelesaian produk cacat dengan memilih tingkat cacat yang ada.

Untuk membuat diagram Pareto, Anda harus mulai dengan kepemilikan data yang dikumpulkan dan dikelompokkan. Langkah-langkah menyusun diagram Pareto adalah sebagai berikut: 
Menentukan masalah apa yang akan diteliti, mengindentifikasi kategorikategori masalah yang akan dibandingkan. Setelah itu, merencanakan dan melaksanakan pengumpulan data.

1. Tentukan jangka waktu yang diperlukan untuk analisis (misalnya bulanan, mingguan atau harian).

2. Catat frekuensi kemunculannya pada daftar periksa

3. Buat daftar pertanyaan dalam urutan frekuensinya (dari tertinggi ke terendah).

4. Hitung frekuensi kumulatif dan persentase kumulatif.

5. Gambarkan frekuensi dalam bentuk grafik batang.

6. Plot persentase kumulatif pada diagram garis

7. Menafsirkan (terjemahan) bagan Pareto.

8. Mengambil tindakan berdasarkan peristiwa / masalah prioritas.

9. Ulangi langkah di atas lagi dan terapkan perbaikan untuk membandingkan hasil.

Maka setelah itu untuk membangun sebuah Diagram Sebab Akibat juga ada beberapa langkah, berikut langkah-langkah dalam menyususn Diagram Sebab Akibat adalah sebagai berikut :

1. Setuju dengan pernyataan masalah

2. Tentukan kategorinya

3. Cari tahu penyebab potensial melalui brainstorming

4. Tinjau dan setujui kemungkinan besar penyebabnya

\section{Hasil dan Pembahasan}

Berdasarkan metode penelitian, langkah pertama adalah melakukan analisis statistik pengendalian kualitas dan membuat checklist, kemudian membuat diagram sebab akibat berdasarkan observasi wawancara. Jika data yang terkumpul sudah terkumpul maka langkah selanjutnya adalah menganalisis data untuk menyelesaikan masalah yang diteliti dan memberikan solusi.

\section{Lembar check sheet kerudung}

Tabel 1.

Hasil Pengumpulan Data November 2020

Lembar Check Sheet

\begin{tabular}{cccccc}
\hline \multirow{2}{*}{ Bulan } & Jumlah & Jenis Kerusakan & $\begin{array}{c}\text { Jumlah } \\
\text { Kerusakan }\end{array}$ & $\begin{array}{c}\text { Jumlah } \\
\text { Presntase } \\
\text { Rusak } \\
(\%)\end{array}$ \\
\cline { 2 - 6 } & & Kain Berkerut & $\begin{array}{c}\text { Warna Tidak } \\
\text { Sesuai }\end{array}$ & \\
\hline Minggu ke 1 & 60 & 5 & 3 & 8 & $13,3 \%$ \\
\hline Minggu ke 2 & 87 & 3 & 3 & 6 & $3,4 \%$ \\
\hline Minggu ke 3 & 103 & 8 & 4 & 12 & $3,8 \%$ \\
\hline Minggu ke 4 & 100 & 7 & 5 & 12 & $5 \%$ \\
\hline Jumlah & 350 & 23 & 15 & 38 & $25,5 \%$ \\
\hline Rata-rata & 87,5 & & & 9,5 & $6,38 \%$ \\
\hline
\end{tabular}

Sumber Data: Data dioleh, 2020 


\section{Diagram pareto pada produk kerudung}

Tabel 2.

Data Diagram Pareto Ketidaksesuaian Produk Kerudung

\begin{tabular}{llllll}
\hline No & Jenis cacat & Frekuensi & $\begin{array}{l}\text { Frekuensi } \\
\text { komulatif } \\
(\%)\end{array}$ & Presentase & $\begin{array}{l}\text { Presentase } \\
\text { komulatif } \\
(\%)\end{array}$ \\
\hline 1. & Warna tidak sesuai & 15 & 15 & $40 \%$ & $40 \%$ \\
\hline 2. & Kain berkerut & 23 & 38 & $60 \%$ & $100 \%$ \\
\hline & & 38 & & $100 \%$ & \\
\hline
\end{tabular}

Sumber Data: Data diolah, 2020

Dari perhitungan diatas dapat diketahui frekuensi dan persentase komulatif, maka langkah selanjutnya ialah dibuat suatu diagram pareto dari tabel 2 sebagai berikut:

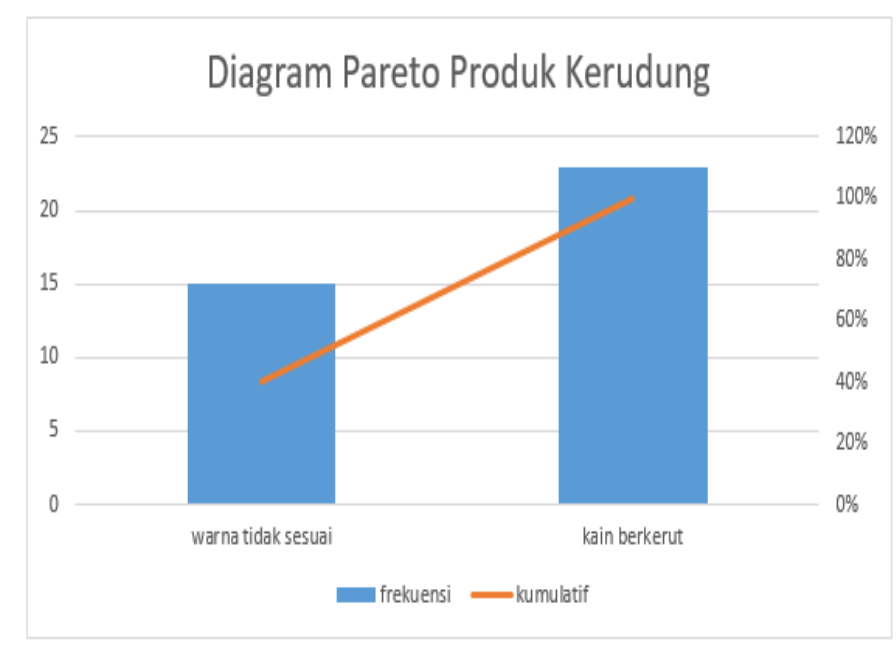

Gambar 1

Diagram Pareto Produk Kerudung

\section{Diagram sebab-akibat (fishbone-diagram)}

Seperti yang dapat dilihat dari analisa diagram pareto diatas, berdasarkan pengamatan yang dilakukan, bagian yang paling penting dari cacat / rusak pada produk kerudung adalah kain yang kusut dan warna yang tidak sesuai. Sedangkan untuk tipe cacat tidak cocok :

1. Kain berkerut adalah ketika ada suatu kesalahan yang terjadi contohnya benang yang ketarik ketika proses pembuatan kerudung dan jahitan bahan nya kurang rapi. 
2. Warna tidak sesuai adalah ketika terjadi human eror contohnya ketika memesan kain yang berwarna merah tetapi barang yang datang yang di pesan tidak sesuai keinginan. Hubungan antara faktor penyebab dengan masalah yang terjadi yaitu cacat yang dominan akan ditunjukan pada diagram sebab akibat dibawah ini :

\section{Warna Tidak Sesuai $40 \%$}

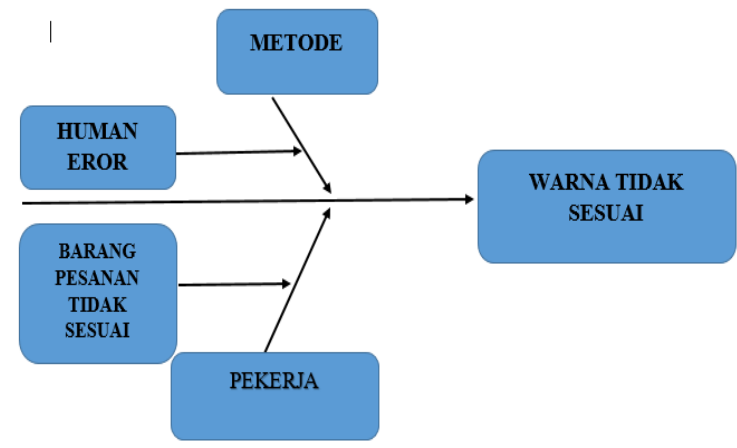

\section{Gambar 2 \\ Diagram Sebab Akibat Warna Tidak Sesuai}

Dari gambar diatas dapat diketahui bahwa warna tidak sesuai disebabkan oleh hal-hal berikut:

1. Metode : Human eror, (pemesanan barang gagal oleh karena itu warna jadi tidak sesuai).

2. Pekerja : Barang pesanan tidak sesuai (para pekerja kurang konsentrasi).

\section{Kain Berkerut $60 \%$}

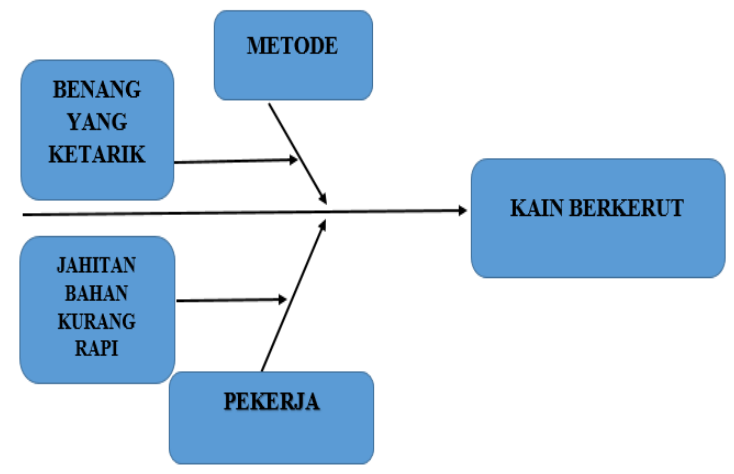

\section{Gambar 3 \\ Diagram Sebab Akibat \\ Kain Berkerut}

Dari gambar diatas, dapat diketahui bahwa kain berkerut di sebabkan oleh hal-hal berikut:

1. Metode : Benang yang ketarik (dalam proses pembuatan kerudung).

2. Pekerja : Jahitan bahan kurang rapi (akibat dari para pekerja yang teledor). 
Upah, Sopyan Saori, Mochamad Maulana Hasan Jaelani, Wahyuni dan Ghivari Lughi Ghartiwa 



\section{Kesimpulan}

Hasil penelitian dan analisis pada perusahaan ANHA store dapat disimpulkan sebagai berikut. Jumlah kerudung yang dihasilkan selama bulan November 2020 sebanyak 350 dan total keseluruhan produk yang gagal atau cacat sebanyak 38. Dengan menganalisis menggunakan diagram pareto, faktor utama yang paling mempengaruhi ketidaksesuaian pada kerudung adalah warna tidak sesuai sebesar $40 \%$ dari jumlah produk gagal secara menyeluruh. Setelah itu dilanjut dengan kain berkerut sebesar $60 \%$. Dengan menggunakan diagram sebab akibat dapat disimpulkan bahwa faktor utama yang menyebabkan kerusakan atau ketidaksesuaian pada pembuatan kerudung adalah manusia dan metode.

Adapun sarannya, sebaiknya perusahaan memberikan instruksi kepada karyawan sebelum melanjutkan ke proses produksi untuk mengurangi tingkat kesalahan yang dilakukan karyawan selama proses produksi. Dengan meminimalisir produk yang cacat atau tidak sesuai, sebaiknya perusahaan ANHA STORE kedepannya dapat menggunakan diagram Pareto dan diagram sebab akibat untuk mengetahui faktor-faktor penyebab kegagalan produk.

\section{BIBLIOGRAFI}

Amanah, Dita. (2010). Pengaruh harga dan kualitas produk terhadap kepuasan konsumen pada majestyk bakery \& cake shop cabang HM Yamin Medan. Jurnal Keuangan \& Bisnis, 2(1), 71-87.

Amilia, Suri. (2017). Pengaruh citra merek, harga, dan kualitas produk terhadap keputusan pembelian handphone merek xiaomi di kota langsa. Jurnal Manajemen Dan Keuangan, 6(1), 660-669.

Asmoko, Hindri. (2013). Teknik Ilustrasi Masalah-Fishbone Diagrams. Magelang Badan Pendidik Dan Pelatih Keuang Dep Keuang.

Fakhri, Faiz, \& KAMAL, Mustofa. (2010). Analisis Pengendalian Kualitas Produksi di PT. Masscom Graphy dalam Upaya Mengendalikan Tingkat Kerusakan Produk Menggunakan Alat Bantu Statistik. Universitas Diponegoro.

Hisprastin, Yasarah, \& Musfiroh, Ida. (2021). Ishikawa Diagram dan. Artikel Mini Review, 6(1), 1-9.

Husni, Amir, \& Putra, M. G. S. Muh Prima. (2018). Pengendalian Mutu Hasil Perikanan. UGM PRESS.

Jani, Rahman, \& SUGIONO, Sugiono. (2014). Analisis Pengendalian Persediaan Bahan Baku Pakan Ternak Sapi Dalam Rangka Efisiensi Dengan Menggunakan Diagram Pareto, Metode EOQ Dan Diagram Sebab Akibat (Studi Kasus Pada PT. Kariyana Gita Utama). Fakultas Ekonomika dan Bisnis.

Myers, Raymond H., Montgomery, Douglas C., \& Anderson-Cook, Christine M. 
Analisis kandungan merkuri $(\mathrm{Hg})$ dan hidrokuinon pada sediaaan krim pemutih wajah

(2016). Response surface methodology: process and product optimization using designed experiments. John Wiley \& Sons.

Nurkarsa, Aldo Adit Hermaya. (2019). Program Aplikasi Penjualan Ban pada Toko Y Berbasis Web. Equivalent: Jurnal Ilmiah Sosial Teknologi, 1(1), 1-4.

Ochiai, Taku, Grimault, Stephan, Scavarda, Didier, Roch, Giorgi, Hori, Tomokatsu, Rivière, Denis, Mangin, Jean François, \& Régis, Jean. (2004). Sulcal pattern and morphology of the superior temporal sulcus. Neuroimage, 22(2), 706-719.

Ratnadi, Ratnadi, \& Suprianto, Erlian. (2020). Pengendalian Kualitas Produksi Menggunakan Alat Bantu Statistik (Seven Tools) Dalam Upaya Menekan Tingkat Kerusakan Produk. Jurnal Industri Elektro Dan Penerbangan, 6(2).

Sukendro, Gatot, Destiarmand, Achmad Haldani, \& Kahdar, Kahfiati. (2016). Nilai Fetisisme Komoditas Gaya Hijab (Kerudung Dan Jilbab) Dalam Busana Muslimah. Jurnal Sosioteknologi, 15(2), 241-254.

Suwandi Ng, fransiskus E. D. (2016). peran kemampuan manajerial sebagai mekanisme peningkatan kualitas laba dan nilai perusahaan jurnal akuntasi dan keuangan Indonesia. 174-193.

Zakariya, Yuza, Mu'tamar, Muhammad Fuad Fauzul, \& Hidayat, Khoirul. (2020). Analisis Pengendalian Mutu Produk Air Minum dalam Kemasan Menggunakan Metode New Seven Tools (Studi Kasus di PT. DEA). Rekayasa, 13(2), 97-102. 